\title{
Transformación de una sociedad cooperativa de trabajo asociado en una sociedad laboral. Especial referencia a los fondos de reserva indisponibles
}

\author{
Encarnación García Ruiz ${ }^{1}$
}

Recibido: 12 de diciembre de 2017 / Aceptado: 31 de enero de 2018

Resumen. En este trabajo intentamos justificar que en el caso de transformación de una sociedad cooperativa de trabajo asociado en una sociedad laboral, se admita legalmente excepcionar el destino de los fondos indisponibles y se permita aportarlos al patrimonio de la laboral, sobre la base de que ambas son sociedades de economía social, participadas y controladas por los trabajadores, gestionadas democráticamente, aunque una sea de base mutualista y, la otra, una sociedad de capital, cuyos regímenes legales son bien distintos, pero ambas, son sociedades de trabajo asociado, con un fuerte carácter intuitu personae que les acerca a los fines sociales propuestos, independientemente de su forma jurídica. Por lo que su transformación supone más una alteración en la estructura patrimonial de la sociedad que en la estructura personal, dado que la misma persona jurídica, seguramente con todos los socios o con la mayoría de ellos, continuarán el mismo proyecto empresarial, aunque bajo otra forma jurídica de muy parecida naturaleza. A lo que se une que ambas tienen la encomienda por la Ley de Economía Social de preservar y difundir este sector económico y social. En definitiva, estaríamos ante una gestión continuada de los fondos bajo otra estructura jurídica.

Palabras clave: Economía social; Sociedad Laboral; Sociedad Cooperativa de trabajo asociado; Transformación; Excepciones legales.

Claves Econlit: K23; K230; J540; M410.

\section{[en] Transformation of an associated work cooperative in a labour company. Special reference to the unavailable reserve funds}

\begin{abstract}
In this paper it will be tried to justify that in the case of transformation of an associated work cooperative into a labour company, to except the destination of the unavailable funds should be legally admitted and it should be allowed to contribute to the patrimony of the labour company, on the basis that both are social economy societies, owned and controlled by workers, democratically managed, although one of them has a mutualist base, and the other one is a capital company, whose legal regimes are very different, but both are associated work societies, with a strong intuition personae character that brings them closer to the proposed social goals, regardless of their legal form. So its transformation is more an alteration in the patrimonial structure than in the personal structure of the company, since the same legal person, with all the members or with most of them, continues the same business project, although in another legal form of very similar nature. Besides to preserve and spread this economic and social sector was entrusted to both of them by the Social Economy Act. To sum up it would be a continued management of funds under another legal structure.
\end{abstract}

$1 \quad$ Universidad de Almería, España

Dirección de correo electrónico: egruiz@ual.es 
Keywords: Social economy; Labour Company; Associated work cooperative; Transformation; Legal exceptions.

Sumario. 1. Introducción. 2. El régimen jurídico de la transformación de una sociedad cooperativa en otro tipo societario. 3. Justificación en la elección de una sociedad cooperativa de trabajo asociado y una sociedad laboral. 4. Problemas patrimoniales en la transformación de una sociedad cooperativa de trabajo asociado en una sociedad laboral. 5. Especial referencia a los fondos de reserva indisponibles. Apuntes para excepcionar su régimen jurídico en caso de transformación de una sociedad cooperativa de trabajo asociado en una sociedad laboral. 6. Las peculiaridades que debería de adoptar el procedimiento de transformación en este caso y las que se debería de introducir en el régimen jurídico de las sociedades laborales. 7. Conclusiones. 8. Referencias bibliográficas.

Cómo citar: García Ruiz, E. (2017) Transformación de una sociedad cooperativa de trabajo asociado en una sociedad laboral. Especial referencia a los fondos de reserva indisponibles. REVESCO. Revista de Estudios Cooperativos, Monográfico, No 126, pp. 57-73. DOI: 10.5209/REVE.59764.

\section{Introducción}

Con la transformación los socios buscan optimizar los recursos económicos y sociales de la persona jurídica y consideran que lo lograran mejor bajo otra forma jurídica.

A nadie se le escapa que el legislador cooperativo ha sido muy reacio a esta modificación estructural de las sociedades cooperativas dada la esencia de las mismas y, la ha ido introduciendo con mucha cautela en las legislaciones sobre cooperativas, tanto nacional como autonómica. Por cuanto la transformación de una sociedad cooperativa en otro tipo social, sobre todo, si de sociedades de capital se trata, supone un cambio radical en el régimen legal de la sociedad cooperativa implicada que afecta directamente a los pilares jurídicos sobre los que se estructura la sociedad.

El régimen jurídico de la transformación de una sociedad cooperativa, cualquiera que sea su clase, también las de trabajo asociado (SCTA), está recogido en el artículo 69 de la Ley 27/1999 de 16 de julio, de cooperativas, (LCoop) que habrá que poner en relación con los artículos 64,65 y 71 de la misma ley antes dicha. También están reguladas en las correspondientes leyes autonómicas sobre cooperativas, no obstante nosotros tomaremos en consideración para este estudio la LCoop.

Mientras que el régimen jurídico de las sociedades laborales (SSLL) está regulado por la Ley 44/2015, de 14 de octubre, de sociedades laborales y participadas (LSLP), que considera a estas sociedades como sociedades de capital, ya sea con forma de anónima o limitada y, como tal, sus modificaciones estructurales están reguladas por la Ley 3/2009, de 3 de abril, sobre modificaciones estructurales de las sociedades mercantiles (LME). ${ }^{2}$

El régimen jurídico de la transformación en la LCoop se articula en torno a un procedimiento formal y a un sistema de garantías para los terceros y para los

2 Las sociedades laborales quedan reguladas además de por su ley específica, la Ley 44/2015 también, en todo aquello que ésta no prevea, por el Real Decreto Ley 1/2010, de 2 de julio, por el que se aprueba el texto refundido de la Ley de Sociedades de Capital (en adelante LSC). 
socios. A los primeros, se les reconoce un derecho de oposición en tanto no se les garantice los créditos pendientes con la sociedad que pretende transformarse. A los segundos, a los socios, si votan en contra de la propuesta de transformación por no estar de acuerdo con los cambios que experimentará su nueva posición jurídica, se les reconoce un derecho de separación y de reembolso de sus aportaciones a la sociedad cooperativa (Macías, 2006). Además, en un intento de preservar la esencia del cooperativismo se establece legalmente la particularidad de no poder repartir ni disponer de algunos fondos de reserva cooperativos.

Dos medidas de corte económico que suponen una carga financiera importante para la sociedad resultante en caso de transformación de una cooperativa en otro tipo societario que han actuado de rémora a la hora de adoptar la decisión de transformarse (Rojo, Esteban y Sánchez, 2001) con el consiguiente riesgo para poder continuar con el proyecto empresarial.

De ahí que para no violentar en exceso la naturaleza propia de las sociedades cooperativas, nuestra propuesta es excepcionar el régimen general de la transformación en caso de una SCTA y permitir que esos fondos puedan transferirse al patrimonio de la resultante si ésta adopta la forma de una sociedad laboral (SL), sobre la base de que ambas son sociedades pertenecientes al sector de la economía social, participadas y controladas por los trabajadores, cuya gestión es democrática, aunque una sea de base mutualista y la otra una sociedad de capital, con regímenes legales bien distintos, pero ambas, son sociedades de trabajo asociado, con un fuerte carácter intuitu personae que les acerca a los fines sociales propuestos, independientemente de su forma jurídica.

\section{El régimen jurídico de la transformación de una sociedad cooperativa en otro tipo societario}

Nuestro derecho positivo asume ya sin ninguna reticencia la transformación de una sociedad cooperativa en otro tipo social sea civil o mercantil de cualquier clase (art. 69 LCoop). En el mismo sentido se expresa la LME que reconoce expresamente que las sociedades cooperativas podrán transformarse en sociedades mercantiles y viceversa (art.1.5 LME). Por tanto, no hay dudas sobre ello ${ }^{3}$. De este modo se facilita el desarrollo de la actividad empresarial cuando la estructura organizativa cooperativa fuera inadecuada para el tamaño de la actividad.

3 No siempre ha sido así, en las leyes de cooperativas anteriores a la vigente, la transformación de la cooperativa en otra sociedad era considerada como una excepción. Vid. Alfonso (1997). El motivo está muy bien resumido por Rosembuj (1995:826), cuando dice que, "el impedimento a la transformación de la sociedad cooperativa en sociedad mercantil es un argumento envejecido de la doctrina cooperativa, clásica, convertido, por razones ignoradas, en dogma de fe." Argumento que principalmente giraba en torno a la falta de ánimo de lucro que debía imperar en estas sociedades. Más recientemente Alfonso, (2002), Sacristán,(2010).

No obstante, esta modificación estructural va siendo aceptada por las distintas leyes autonómicas sobre cooperativas hasta ser reconocida con carácter general por la Ley general de cooperativas de 1999 y por todas las leyes autonómicas sobre cooperativas a medida que el régimen jurídico de éstas iba también consolidándose como una sociedad mercantil y confluyendo su regulación con importantes aspectos de las sociedades de capital, desvaneciéndose finalmente cualquier reticencia en equiparar a las sociedades cooperativas con cualquier otro tipo social que les permitiera una mejor realización del proyecto empresarial. En este sentido Suso (2002) y la bibliografía allí citada. También, León (2009) o Rodríguez (2002). 
Mayor problema presenta el régimen jurídico de la transformación que queda excluido de esa norma y remite en lo referente a los requisitos y efectos de la transformación de la sociedad cooperativa a la legislación que le sea aplicable (art. $7 \mathrm{LME}$ ). Se apunta a que una de las razones por la que la transformación de una sociedad cooperativa queda excluida de las LME puede ser por el problema de las competencias autonómicas (González-Meneses, 2013:22; Alfonso, 1995:188; Sacristán, 2010).

La LCoop dedica a la transformación solo el artículo 69 cuya parca redacción plantea importantes carencias de difícil resolución práctica ${ }^{4}$, ya que se limita a ordenar que el acuerdo de transformación deberá ser adoptado por la Asamblea General y a establecer dos cautelas de tipo económico, como son, de una parte, reconocer el derecho de separación del socio que vote en contra del acuerdo y al reintegro de sus aportaciones, remitiendo para ello a lo dispuesto para la fusión (art.69.2 LCoop). Cuyo procedimiento no siempre tiene un fácil encaje cuando se trata de transformar una sociedad cooperativa en una sociedad de capital como es la SL. Y, de otra parte, "en el supuesto de transformación de una sociedad cooperativa en otro tipo de entidad, los saldos de los fondos de reserva obligatorio, el fondo de educación y cualquiera otro fondo o reservas que estatutariamente no sean repartibles entre los socios, recibirán el destino previsto en el artículo 75 de esta Ley para el caso de liquidación de la cooperativa" (art. 69.6 LCoop.). Cuando estas dos operaciones son bien distintas, ya que con la primera la persona jurídica persigue continuar produciendo bienes o servicios para el mercado, mientras que el propósito de la segunda es liquidar a la persona jurídica.

Es obvio que la primera disposición busca garantizar al socio cooperativo la posibilidad de abandonar el proyecto colectivo con la menor merma económica para él, a la vez que se da cumplimiento al principio de puerta abierta que rige en las cooperativas y que se concreta en libre adhesión y baja voluntaria. Derecho de separación que no es exclusivo de este tipo societario, puesto que también está reconocido en la transformación de sociedades de capital (art. $15 \mathrm{LME}$ ), remitiendo al Título IX de la LSC, cuyas causas y procedimientos son relativamente parecidas.

No obstante, como se sabe, sus consecuencias económicas pueden suavizarse tras la Ley 16/2007, de 4 de julio, de reforma y adaptación de la legislación mercantil en materia contable para su armonización internacional con base en la normativa de la Unión Europea 5 .

Mientras que con la segunda disposición, el interés perseguido por el legislador declarando la irrepartibilidad de los fondos de reserva, busca proteger la esencia del cooperativismo y evitar que los fondos que se han ido generando a lo largo de la vida de la cooperativa salgan del mundo cooperativo y aprovechen solo a unos pocos, lo que puede ser lógico en la transformación de una cooperativa en otro tipo societario, no lo es tanto en los dos modelos societarios que proponemos como

4 Si bien es cierto que casi todas las leyes de cooperativas de las comunidades autónomas son más recientes, y algunas como la Ley andaluza le dedican una mayor atención reglamentaria a esta modificación estructural, lo hace en cuanto al procedimiento sin que se aprecien cambios sustanciales en cuanto a los derechos de los socios cooperativos y destino de los fondos.

5 Mucho se ha escrito sobre las consecuencias que tendría para las cooperativas el nuevo criterio contable introducido por esta norma. Por todos, vid. Vargas, Gadea, Sacristán, (2017). 
intentaremos justificar seguidamente. Por lo que la generalización no parece ser la pauta legal más aconsejable.

\section{Justificación en la elección de una sociedad cooperativa de trabajo asociado y una sociedad laboral}

Las similitudes de estos dos tipos societarios han sido ya puestas de manifiesto por la doctrina hasta el punto de que en muchas ocasiones se estudian conjuntamente. Debido a que una vez que la sociedad de capital (anónima o de responsabilidad limitada) adquiere la condición administrativa de laboral, ambas quedan incluidas en el sector de la economía social [art. 5 de la Ley 5/2011, de 29 de marzo de Economía social, (LES)], que les aúna en cuanto a los principios sobre los que deben orientar su gestión (art. 4 LES). ${ }^{6} \mathrm{Y}$, a que ambas son de naturaleza personalista, dado que se articulan en torno al trabajo cooperativo de sus socios para producir bienes o servicios para el mercado que quedan así unidos por un vínculo social y laboral, que claramente nos permite hablar en las sociedades laborales de la doble condición de socio y trabajador, no así en las cooperativas de trabajo asociado.

Además, como hemos avanzado, sus regímenes jurídicos exigen que éstas sean sociedades participadas y controladas por sus trabajadores y que sean gestionadas democráticamente $^{8}$. Y en ambos tipos societarios se admite que puedan ser ayudados en su actividad empresarial por otros trabajadores asalariados no socios, si bien, preservando el carácter personalista de ambos tipos societarios se impone legalmente límites a la contratación de mano de obra asalariada?

La mayor diferencia que presentan estas sociedades es en torno al capital social, a sus títulos de representación y al conjunto de derechos y obligaciones que estos

6 Para un estudio más detenido de las diferencias y similitudes entre ambos tipos societarios desde esta perspectiva Lejarriaga, (1995).

7 Tradicionalmente se niega al socio cooperativo de trabajo asociado esta doble condición de socio y trabajador sobre la base de que las mensualidades recibidas son a cuenta de los beneficios o excedentes que corresponda a cada socio. Así Paz, (1994), o Llobregat, (1991). Sin embargo algunas normas lo denominan anticipos laborales como la LCPV, art. 99.6 o la LCCat. Art. 132.2. En contra el artículo 80.4 LGC 1999 o la LCAnd., ésta última expresamente considera que esos anticipos no tienen la consideración de salario, si bien, estos deben respetar los derechos y garantías legalmente establecidos en el derecho laboral común. También algunos autores hablan de esa relación laboral, como Santiago, (1998). No obstante, esta consideración escapa al objeto de nuestro trabajo por lo que no entraremos en ella.

8 "Son cooperativas de trabajo asociado las que teniendo por objeto proporcionar a sus socios puestos de trabajo, mediante su esfuerzo personal y directo, a tiempo parcial o completo, a través de la organización en común de la producción de bienes o servicios para terceros. También podrán contar con socios colaboradores. La relación de los socios trabajadores con la cooperativa es societaria" (art. 80 LSCoop. 1999). Las aportaciones de cada socio no podrá exceder de un tercio del capital social (art. 45.6 LSCoop. 1999). Mientras que el artículo 1 de la LSLP define a estas sociedades como: aquellas sociedades anónimas o de responsabilidad limitada que pueden obtener la calificación de laboral cuando al menos la mayoría del capital social sea propiedad de los trabajadores que presten en ellas servicios retribuidos de forma personal y directa, en virtud de una relación laboral por tiempo indefinido. Sin que ninguno de ellos puedan ser titulares de acciones o participaciones sociales que representen más de la tercera parte del capital social.

$9 \quad$ El número de horas al año realizadas por trabajadores con contrato de trabajo por cuenta ajena no podrá ser superior al 30 por 100 del total de horas al año realizadas por los socios trabajadores (art. 80.7 LGC 1999). Mientras que en las sociedades laborales, el número de horas al año trabajadas por los trabajadores contratados por tiempo indefinido que no sean socios no podrá ser superior al 49 por 100 del cómputo global de horas al año trabajadas en la sociedad laboral por el conjunto de los socios trabajadores (art. 1.c LSLP). 
transfieren a sus titulares. Para el caso que nos ocupa, será la diferencia en torno a los principios y funciones que cumple el capital social en uno y otro tipo societario, el que más trastornos puede plantear en caso de transformación de una SCTA en una SL.

En la SCTA el capital social es variable y es propiedad de los socios trabajadores, por lo que no cumple con las mismas funciones que en las sociedades de capital. Mientras que en la SL, como en cualquier sociedad de capital, se exige un capital mínimo fundacional y funcional y es propiedad de la sociedad, por lo que es un recurso integrado en el patrimonio neto de ésta que nada debe a los socios en caso de marcha de éstos. Es decir, que en el nuevo tipo social el capital social se convierte en el eje sobre el que se articula los derechos y obligaciones de los socios, al contrario que en la cooperativa donde el capital no cumple las mismas funciones (Suso, 2002).

A pesar de ello, la transformación de una SCTA en una SL supone más una alteración en la estructura patrimonial de la sociedad que en la estructura personal, ya que la misma persona jurídica, seguramente con todos los socios o con la mayoría de ellos, continuaran el mismo proyecto empresarial que, aunque sea bajo otra forma jurídica es de muy parecida naturaleza jurídica.

\section{Problemas patrimoniales en la transformación de una sociedad cooperativa de trabajo asociado en una sociedad laboral}

En caso de transformación de una SCTA en una SL que es lo que aquí nos interesa, el sistema garantista de la legislación cooperativa plantea dos cuestiones que en última instancia, van a revertir en el patrimonio de la SL resultante de la transformación.

La primera cuestión es que los socios cooperativos participaran en el capital social de la laboral en forma proporcional al que tenían en la cooperativa (art. 69.2 LCoop). En la práctica, con carácter general, es difícil medir esta proporcionalidad ya que las aportaciones de capital tienen distinta naturaleza jurídica en uno y otro tipo social ${ }^{10}$. Sin embargo, consideramos que en una SCTA puede tener menos dificultad establecerla y podría seguirse para ello dos caminos. Uno sería que la proporcionalidad se ciñera a las aportaciones de capital exclusivamente, y que la remuneración a cuenta de beneficios que el socio recibe en la cooperativa por las aportaciones de trabajo, pasara de igual forma a la laboral pero a título de salario. No olvidemos la doble condición de socio y trabajador por cuenta ajena en la sociedad laboral. Teniendo en cuenta que ningún socio de la laboral podrá tener una participación superior a la tercera parte del capital social [art.1.2,b) LSLP]. Otro camino sería introducir en la aportación de capital el valor económico (la remuneración a cuenta de beneficios) del trabajo desempeñado en la cooperativa

10 Suso, (2002), ya advertía en nota a pie 22 que: "Esta opción puede tener el mérito de ir acostumbrando al socio de la cooperativa a lo que va a ser sus status en la sociedad transformada, pero desde luego, no guarda concordancia con la forma de medir sus derechos, obligaciones e intereses en la cooperativa, que, como es sabido, se establece básicamente en función de la actividad cooperativizada por cada socio. ....En estos casos habrá que entender que la regla a seguir debe ser la que fija sólo el capital titularizado en la cooperativa, como módulo para establecer la participación en la nueva sociedad anónima o limitada.” 
por cada socio además de sus aportaciones de capital. Puede servir para medir la proporcionalidad, salvando las distancias, lo dispuesto en el apartado 2 del artículo 12 de la LME para el socio industrial, que admite que la participación de éstos en el capital de la nueva sociedad transformada puede ser la que se convenga entre los socios. En esa libertad los socios podrán establecer el porcentaje de capital que tendrán en la laboral.

La segunda cuestión, como ya hemos avanzado, es que los socios cooperativos que voten en contra del acuerdo de transformación, tienen reconocido un derecho de separación con el mismo tratamiento legal que una baja justificada (art. 15 LME y 65 LCoop) y, por tanto, tendrán derecho a que se les reembolse el valor acreditado de sus aportaciones de carácter obligatorio y voluntario al capital social, una vez deducidas las pérdidas imputadas e imputables al socio (art. 51 LCoop). Siendo la SL resultante la que queda obligada a liquidar las aportaciones al socio o socios disconformes (art. 65.2 LCoop). Lo que, como también hemos apuntado, de ejercer ese derecho varios socios, supondrá una merma para el patrimonio social de la resultante o un mayor esfuerzo económico de los socios cooperativos que han votado a favor y que se integraran en la SL a fin de impedir que ésta quede descapitalizada.

No obstante, este obstáculo puede verse atemperado por vía de los estatutos sociales si estos consideran el capital social de la SCTA en todo o en parte como patrimonio neto y, por tanto, propiedad de la sociedad y no del socio, por lo que en caso de baja justificada del socio nada o solo parte se le devolverá (Martín, Lejarriaga, Iturrioz, 2007). Ya que el capital social puede estar constituido por aportaciones cuyo reembolso en caso de baja puede ser rehusado incondicionalmente por el Consejo Rector [art.45.1,b) LCoop].

Esta opción facilitará la protección del patrimonio social en caso de transformación si hubiera socios disconformes. Aunque, seguramente esto será viable si la SCTA se ha constituido con esta mención estatutaria, porque de lo contrario, la transformación obligatoria de las aportaciones con derecho de reembolso en caso de baja en aportaciones no reembolsables, necesita el acuerdo con mayoría reforzada de la Asamblea General. En éste caso el socio disconforme puede darse de baja y será considerada como baja voluntaria [art. 451,b) LCoop].

Si la causa de transformar la naturaleza de la aportación es la transformación de la SCTA estaremos en la misma situación, el socio disconforme con la transformación lo estará también con el acuerdo de transformar la naturaleza de su aportación. Esta falta de previsión estatutaria difícilmente podrá subsanarse en caso de transformación.

De tal forma, que de haber socios disidentes con derecho de reembolso, es la SL la obligada a liquidar sus aportaciones dentro del mes siguiente a la fecha en que haya ejercido ese derecho (art. 65.2 LCoop). Hasta que no haya pagado las correspondientes liquidaciones no podrá la SL formalizar la transformación (art. 67 LCoop). Un breve plazo que contrasta con el de cinco años como máximo propuesto legalmente para el reembolso de las aportaciones en caso de baja voluntaria de la cooperativa.

Y no es de extrañar que pueda haberlos, dado que el régimen general de las SSLL prevé un rígido procedimiento de transmisión de las acciones o participaciones sociales en que se divide el capital social (art. 6 LSLP) y, por tanto, 
no se dan las circunstancias que desaconseja el ejercicio de ese derecho, en previsión de un posible aumento de valor de las mismas en una posterior transmisión tras la transformación (Vargas, Gadea y Sacristán, 2017). Aunque esto también nos va a permitir justificar la excepción planteada inicialmente.

\section{Especial referencia a los fondos de reserva indisponibles. Apuntes para excepcionar su régimen jurídico en caso de transformación de una sociedad cooperativa de trabajo asociado en una sociedad laboral}

Como hemos avanzado uno de los principales escollos denunciados por la doctrina que dificultan las operaciones de transformación que nos ocupa es el destino que hay que dar a los fondos no repartibles entre los socios, como son, los saldos de los fondos de reserva obligatoria (FRO), los Fondos de Educación y Promoción (FEP) y cualesquiera otro fondo o reservas que estatutariamente no sean repartibles entre los socios (art. 69.6 LCoop). Esos no pasan al patrimonio de la nueva sociedad, ya que deben ponerse a disposición de la sociedad cooperativa o entidad federativa que figure expresamente recogida en los estatutos sociales o que se designe por acuerdo de la Asamblea General y, a falta de ello, deberá ingresarse en la institución pública competente. Con la finalidad de destinarlos a la constitución de un fondo para la Promoción del Cooperativismo [art. 75.2, d) LCoop] ${ }^{11}$. Finalidad que es muy loable en caso de extinción de la sociedad pero que nos crea ciertas dudas sobre su conveniencia en caso de transformación de una SCTA en una SL. Ya que en este tipo de transformación $\mathrm{y}$, sin grandes concesiones del régimen cooperativo, puede quedar justificada, tanto desde una perspectiva de política jurídica como de técnica jurídica, la propuesta inicial que hacíamos de excepcionar el destino de estos fondos.

\subsection{Justificación desde la perspectiva de política jurídica}

El destino de estos fondos, principalmente el FRO y el FEP, en caso de liquidación están enraizados con los principios configuradores y esenciales de las cooperativas y esto sirve de base para justificar la indisponibilidad de los mismos (Suso, 2002:4875). Son razones ideológicas las que históricamente ligan estos fondos a los fines cooperativos que buscan la promoción y mantenimiento de los intereses económicos y sociales, tanto de los individuos que componen la cooperativa, como de toda la comunidad o entorno social (Ulazia, 2003). Con ellos se busca promocionar el movimiento cooperativo precisamente para preservarlo y defender su esencia. Por eso se impide que estos fondos salgan del mundo cooperativo y, en caso de extinción de la cooperativa, éstos obligatoriamente se tienen que poner a disposición de otras instituciones que quedan encargadas de reinvertirlos en esa promoción $^{12}$.

11 Lo que puede suponer un desequilibrio entre el patrimonio y el capital social. León, (2009).

12 Lo que ha sido criticado por la doctrina. Vid., entre otros, Rosembuj, op. cit. 
A nuestro modo de ver, este mismo interés de promoción y difusión late en el sector de la economía social materializado en sus principios orientadores ${ }^{13}$, que no olvidemos se inspiran en los principios cooperativos. Debido a que las SSLL tienen las mismas necesidades y obligaciones, aunque no cuenten con los mismos instrumentos, (FRO y FEP), para garantizar la efectiva aplicación de esos principios.

El FEP tiene como finalidad mientras pervive la Cooperativa, la formación y educación de sus socios y trabajadores en los principios y valores cooperativos y, también, en materias específicas de su actividad societaria o laborales y demás actividades cooperativas [art. 56.1, a) LCoop]. Esta finalidad es perfectamente extrapolable a las necesidades que tiene una SL, en ella se hace especialmente necesario, de una parte, la formación continua de sus trabajadores que también son socios y directivos de la SL y, de otra parte, queda obligada a generar empleo estable y de calidad, además de servir de instrumento para la cohesión social que favorezca el compromiso con el desarrollo local [art. 4.c) LES y art. 18.3,c) LSLP], en claro paralelismo con la segunda y tercera tarea encomendada a estos fondos por el artículo 56.1, b) y c) de la LCoop referente a la difusión del cooperativismo y la promoción cultural, profesional y asistencial del entorno local y de la comunidad en general.

En la misma dirección se expresan las distintas asociaciones de las SSLL en cuanto a la necesidad permanente de difundir los principios y valores propios del modelo de gestión social de éstas sociedades en particular ${ }^{14}$. Y, en general, de los beneficios del sector de la economía social como alternativa al sistema capitalista imperante, porque ya no es tarea exclusiva y excluyente del movimiento cooperativo. En su auxilio han venido las organizaciones de la economía social y, entre ellas, por tanto, las SSLL ${ }^{15}$.

13 Ley 5/2011, de 29 de marzo, de Economía Social.

Artículo 4. Principios orientadores.

Las entidades de la economía social actúan en base a los siguientes principios orientadores:

a) Primacía de las personas y del fin social sobre el capital, que se concreta en gestión autónoma y transparente, democrática y participativa, que lleva a priorizar la toma de decisiones más en función de las personas y sus aportaciones de trabajo y servicios prestados a la entidad o en función del fin social, que en relación a sus aportaciones al capital social.

b) Aplicación de los resultados obtenidos de la actividad económica principalmente en función del trabajo aportado y servicio o actividad realizada por las socias y socios o por sus miembros y, en su caso, al fin social objeto de la entidad.

c) Promoción de la solidaridad interna y con la sociedad que favorezca el compromiso con el desarrollo local, la igualdad de oportunidades entre hombres y mujeres, la cohesión social, la inserción de personas en riesgo de exclusión social, la generación de empleo estable y de calidad, la conciliación de la vida personal, familiar y laboral y la sostenibilidad.

d) Independencia respecto a los poderes públicos.

14 Sirva de ejemplo las Resoluciones del III Congreso de la Agrupación de Sociedades Laborales de Euskadi (ASLE), 2013 contenidas en Tiempo de Crisis Tiempo de Oportunidades: La Sociedad Laboral del siglo XXI. Agrupación de Sociedades Laborales de Euskadi, p.54. En el mismo sentido, la Fundación EOI (2013) en la Participación Financiera de las personas trabajadoras en la empresa, EOI, p.7, deja constancias de la necesidad de "promover la cultura participativa como palanca que favorece el cambio, que mira otro modelos de empresa más eficaz, responsable, más solidario y con más perspectiva territorial...."

15 En este sentido, Macías, (2015:10), quien considera que “..es la propia administración pública quien potenciando la economía social, indirectamente potencia el cooperativismo...” 
Es decir, que hay un paralelismo claro entre los fines a que debe destinarse este FEP según lo dispuesto en el artículo $56 \mathrm{LCoop}^{16}$ y los fines sociales que debe perseguir la SL (art. 4 LES y 18 LSLP).

A lo que se une, que la carga ideológica que sustentaba la prohibición de disponer de estos fondos de forma contraria a la finalidad prevista en las leyes cooperativas, va dando paso a posturas legales más flexibles aceptándose excepciones puntuales a la hora de determinar el destino de los mismos, sobre todo respecto al FRO, así por ejemplo, en caso de transformación de una sociedad "...cooperativa de crédito en otra entidad de crédito, el Fondo de Reserva Obligatorio de aquella pasará a integrarse en el capital social de la entidad resultante de la transformación." (Dis. Final $\left.4^{\mathrm{a}} \mathrm{LME}\right)$.

En el mismo sentido avanzan otras leyes autonómicas como la LCAnd ${ }^{17}$, que en caso de transformación permite poder disponer del cincuenta por ciento del FRO, salvo que los estatutos sociales hayan establecido la irrepartibilidad del total de éste y entonces sí tiene que ponerse íntegramente a disposición de la Administración andaluza (78.2 LCAnd). O, la LCEx ${ }^{18}$ que, en caso de transformación, el destino de los fondos no repartibles será el mismo que prevé para el proceso de liquidación (art. 78 LCEx) y, en este caso, todo el activo sobrante y el remanente del FRO será repartible entre los socios de acuerdo al procedimiento establecido en el mismo artículo (art. 105. 3,3 $3^{\circ} \mathrm{LCEx}$ ).

Especial importancia tiene también lo dispuesto en la $\mathrm{LCCat}^{19}$ que permite el reparto del fondo de reserva obligatorio en el momento de la liquidación de la cooperativa o en el caso de la transformación de esta en otro tipo de sociedad. Sin embargo, en el caso de la transformación, el fondo solo se puede repartir en forma de participaciones o acciones de la nueva sociedad en función de la actividad cooperativizada (art. 83.4 LCCat). O lo dispuesto en la LCEus ${ }^{20}$, que en caso de transformación, admite que el valor nominal de las dotaciones del FRO y de las reservas voluntarias irrepartibles se conviertan en títulos de cuentas en participación en la sociedad resultante (art. 85 .4 LCEus).

Por lo expuesto es fácil concluir, que hay una nueva tendencia hacia un cambio de política legislativa en cuanto a la posibilidad de fijar otro destino a los fondos indisponibles. Superando así viejos argumentos dogmáticos que no siguen teniendo razón de ser en el actual contexto socio económico ${ }^{21}$.

Además, estas soluciones intermedias permitirían proteger de forma más racional todos los intereses en juego. El del socio disidente, porque al ejercer su derecho de separación ha obtenido los derechos económicos que le corresponden; el resto de socios (que seguramente serán la mayoría por no decir todos), que van a

16 1. El fondo de educación y promoción se destinará, en aplicación de las líneas básicas fijadas por los Estatutos o la Asamblea General, a actividades que cumplan alguna de las siguientes finalidades:

a) La formación y educación de sus socios y trabajadores en los principios y valores cooperativos, o en materias específicas de su actividad societaria o laboral y demás actividades cooperativas.

b) La difusión del cooperativismo, así como la promoción de las relaciones intercooperativas.

c) La promoción cultural, profesional y asistencial del entorno local o de la comunidad en general, así como la mejora de la calidad de vida y del desarrollo comunitario y las acciones de protección medioambiental.

17 Ley 14/2011, de 23 de diciembre, de Sociedades Cooperativas Andaluzas.

18 Ley $2 / 1998$, de 26 de marzo, de Sociedad Cooperativa de Extremadura.

19 Ley $12 / 2015$ de 9 de julio, de cooperativas. Comunidad autónoma de Cataluña.

20 Ley 4/1993, de 24 de junio, de Cooperativas de Euskadi.

21 Distinto autores han llamado la atención sobre ello. Entre otros, Gadea, Sacristán, Vargas (2009: 654). 
continuar a través de la misma persona jurídica el mismo proyecto empresarial aunque bajo otra forma jurídica, porque no se van a ver despojados de esos fondos que han ido generando con su esfuerzo durante la vida de la cooperativa y, por último, el movimiento cooperativo tampoco pierde, pues al ser la transformada un tipo social de la economía social esos fondos van a destinarse a la misma finalidad como trataremos de justificar seguidamente.

\subsection{Justificación desde la perspectiva de técnica jurídica}

A pesar de que el destino de estos fondos es el mismo en caso de transformación, desde ésta perspectiva es conveniente ordenar los fondos atendiendo a su naturaleza y finalidad atribuida legalmente mientras pervive la sociedad cooperativa, así, de una parte, distinguimos los saldo de los fondos de reserva obligatoria y cualesquiera otro fondo o reservas que estatutariamente no sean repartibles entre los socios $\mathrm{y}$, de otra parte, los fondos de educación y promoción.

En cuanto a los primeros, durante la vida de la sociedad cooperativa están destinados a prever posibles necesidades económicas futuras, así como servir de garantía a terceros, mostrando la fortaleza financiera de la cooperativa como complemento al capital social que, como sabemos, es variable y responde al principio cooperativo de puertas abiertas. En cierta correspondencia con los fondos de reserva obligatorios (art. 274 LSC) y voluntarios de las sociedades de capital a que está obligada también la SL y con parecida finalidad, pues estos están destinados a enjugar las pérdidas que la sociedad pueda tener en ejercicios económicos futuros para tranquilidad de los terceros, además de las funciones intra societatis que cumple el capital social en éstas sociedades.

A lo que hay que sumar que las SSLL también están obligadas a constituir un fondo de reserva especial que solo puede destinarse a "...la compensación de pérdidas en el caso de que no existan otras reservas disponibles suficientes para ese fin, y/o a la adquisición de sus propias acciones o participaciones sociales, que deberán ser enajenadas a favor de los trabajadores de la sociedad con contrato por tiempo indefinido..." (art. 14.2 LSP), con la intención de que los trabajadores que así lo deseen sean cuanto antes socios de la laboral.

Teniendo en cuenta lo expuesto puede ser una buena solución técnica que se traspase e integre los saldos de los fondos no repartibles entre los socios en el fondo de reserva especial, por ser de parecida estructura social al cooperativo y porque ambos responden al general deseo de conservar, consolidar o desarrollar el patrimonio de la sociedad para alcanzar los fines sociales propuestos. Insistimos que es bien distinta la transformación entre estos dos tipos sociales del sector de la economía social y la transformación de una sociedad cooperativa en otro tipo de sociedad de capital y, por supuesto, dista mucho de una operación de liquidación que lleva a la extinción de la persona jurídica.

A nuestro modo de ver con esta propuesta no estaríamos ni repartiendo los fondos (como está prohibido por ley), ni tampoco los estaríamos usurpando a la persona jurídica que los ha ido formando a lo largo de su trayectoria empresarial, por cuanto sabemos que, "en virtud de la transformación un tipo social adopta un 
tipo social distinto, conservando su personalidad jurídica” (art. $3 \mathrm{LME}{ }^{22}$. Ni se los estaríamos usurpando al movimiento social que también defiende la SL.

Además, al estar sometidos estos fondos de reserva especial a una finalidad muy concreta, se reduce la posibilidad de que los socios den un tratamiento diferente a este haber social y quedarían neutralizados los temores apuntados por algún sector doctrinal de utilizar la posibilidad de usar la transformación con fines torticeros (Alfonso, 1997), al mismo tiempo que se preserva la carga ideológica que conlleva el destino del FRO.

Tratándose de los segundos, del Fondo de Educación y Promoción (FEP), ya hemos avanzado el paralelismo existente entre la finalidad prevista para estos en el artículo 56 de la LCoop y las necesidades de formación, promoción y difusión de los principios y valores en que se asientan las SSLL. Y, si bien no hay un fondo específico para este menester en las SSLL, se podría solventar la cuestión en caso de transformación de una SCTA en una SL, si ésta quedara obligada a introducir en el proyecto de transformación la creación de un fondo voluntario donde destinar el importe del FEP, cuya finalidad educativa sería la misma hasta agotar su importe. La SL puede acomodar perfectamente sus necesidades a las finalidades previstas en el artículo 56 LCoop.

De acuerdo con lo expuesto podría quedar justificada la aportación de estos fondos al patrimonio resultante de la transformada. Además quedaría solventado también el principal escollo legal al que nos enfrentamos en estos casos, como es a su consideración de fondos inembargables e irrepartibles, incluso en caso de liquidación de la cooperativa (art. 56.6 LCoop). Ya que en este supuesto no se reparten los fondos, solo se van a transferir a un fondo parecido en la SL resultante que quedaría destinado a la misma finalidad que tenían en la sociedad cooperativa, e incluso se puede establecer legalmente la cautela de que éste no pueda destinarse a ningún otro propósito hasta su extinción. En nuestra opinión quedarían perfectamente salvados los fines de política jurídica a los que responde su constitución y no tiene mucho sentido ni parece justificado la sustracción, a todos los socios o a la mayoría de ellos, del esfuerzo económico que ha realizado la misma persona jurídica durante los años que ha mantenido la forma de SCTA que continúa el mismo proyecto empresarial, aunque ahora bajo la forma jurídica de SL. Es decir, sería una gestión continuada de estos fondos bajo otra estructura jurídica.

Por ello entendemos que ni siquiera es necesario derogar el carácter de irrepartible e inembargables de estos fondos, porque no se están repartiendo y pueden seguir siendo inembargables en la SL, como otra especialidad más de su régimen jurídico hasta, que éstos sean extinguidos si, acaso la SL así lo previera estatutariamente una vez agotados los mismos. Con ello se lograría proteger y promover la economía social que en definitiva es la finalidad que subyace en el destino de estos fondos y además facilitaría la transformación entre sociedades de economía social. Evitándose también que la sociedad adoptase una política contable y financiera que busque sistemáticamente que no haya excedentes porque se opera con el ideal de beneficio cero para paliar esos inconvenientes (Vargas,

22 Rosembuj (1995:829), ya advirtió que esto permitía "una apropiación larvada del ahorro corporativo por parte de instancias, aunque legítimas, ajenas al interés económico de los socios." 
2008) y sortear que los socios no dispongan de sus beneficios (Rosembuj, 1995), lo que también evitaría la despatrimonialización de la SL resultante y podría seguir desarrollando el proyecto empresarial con ciertas garantías de éxito.

Pero, sobre todo, porque en la transformación entre estos tipos sociales el fin cooperativo y la causa societatis se mantiene.

\section{Las peculiaridades que debería de adoptar el procedimiento de transformación en este caso y las que se debería de introducir en el régimen jurídico de las sociedades laborales}

Nos detendremos en el procedimiento de transformación al solo efecto de introducir las peculiaridades que entendemos permitirían formalmente la transmisión del FRO y el FEP y de cualquier otro fondo irrepartible a la nueva sociedad. De este modo, en el caso que nos ocupa, habría que distinguir dos momentos temporales bien definidos, antes del acuerdo de transformación y después del mismo. Antes de aprobar la transformación el procedimiento a seguir es el mimo que para la fusión (art. 65.2 LCoop).

Así el Consejo Rector de la SCTA que se transforma debe de redactar un proyecto de transformación que además de contener las menciones previstas en el artículo 63 de la LCoop, en nuestro caso, debería introducirse como peculiaridad un nuevo apartado en el que se dejara bien claro en qué fondos de la SL quedarían integrados los saldos de cada uno de los fondos cooperativos y qué destino legal y estatutario se les tiene que dar. Es importante que este apartado contenga cumplida información sobre cómo y porqué, el saldo del FRO se integrará en el Fondo de reserva especial de la laboral y se diluirá en él, dado que éste deberá de dotarse con el diez por ciento del beneficio líquido de cada ejercicio, al menos hasta que alcance una cifra superior al doble del capital social (art.14 LSLP). Mientras que para el saldo del FEP habría la necesidad de crear un fondo específico que estaría sometido a finalidad. Única forma de que los socios tengan la mayor y más precisa información sobre los mismos a la hora de votar el proyecto de transformación.

Al publicarse la convocatoria de la Asamblea General que debe aprobar la transformación deberán ponerse a disposición de los socios, el proyecto de transformación que contendrá puntual información sobre la conveniencia y efectos de la transformación proyectada, el balance de cuentas de pérdidas y ganancias y la memoria explicativa de los tres últimos ejercicios de la cooperativa y el proyecto de Estatutos que regirá en la SL, con las menciones formales y facultativas que exige y permite el régimen jurídico de ésta (art. 63.7 LCoop). Ese proyecto de Estatutos debería recoger una cláusula que contuviera la creación del fondo de formación y el destino que se le dará al mismo mientras dure ese fondo, con especial mención de su extinción una vez agotado su saldo si así lo consideran oportuno los socios. Ahora bien, para que esto fuera posible es necesario que previamente se introduzca en la legislación cooperativa esta posibilidad o excepción.

El acuerdo de transformación deberá ser adoptado por la mayoría de los dos tercios de los votos presentes y representados. Este acuerdo debe ser formalizado mediante escritura pública e inscribirlo en el Registro de Sociedades Cooperativas 
quién anotará el asiento de cancelación de la cooperativa para que la transformación produzca todos sus efectos (art.64.1 y 4 LCoop).

A partir de aquí la sociedad continuará su trayectoria bajo el régimen jurídico previsto para la SL. Éstas por su doble condición de sociedad de capital y de economía social están sometidas a un régimen especial de doble inscripción, en el Registro mercantil y en el Registro de sociedades laborales y no podrán inscribirse en el Registro mercantil como SL si no aportan un certificado de concesión administrativa de esa calificación. La competencia administrativa para calificar, controlar el cumplimiento de los requisitos para mantener dicha calificación o, en su caso, descalificar a la sociedad como laboral, reside en el Registro de sociedades laborales (art.2 LSLP). Por tanto, admitida la excepción legal que venimos planteando en caso de transformación, será el Registro de sociedades laborales el encargado de supervisar que se han cumplido los requisitos formales que requiere la materialización de la excepción. Así mismo, con el fin de evitar situaciones fraudulentas por un mal uso de esos fondos una vez transformada la SCTA en SL, puede introducirse en el régimen jurídico de éstas, una nueva causa de descalificación de laboral (art. 15 LSLP), referente a que si no se dan a esos fondos el destino previsto en los Estatutos sociales, la SL incurriría en causa de descalificación, quedando el Registro de sociedades laborales encargado a través de la técnica de la autorización de controlar y vigilar si efectivamente la SL está aplicando correctamente esos fondos, lo que puede hacerse exigiendo a la SL el depósito anual de la documentación que reglamentariamente se considere oportuno para justificar el uso adecuado de los mismos. Al estilo, aunque salvando las distancias, del depósito de cuentas anuales en el Registro mercantil.

\section{Conclusiones}

La transformación de una SCTA en una SL queda regulada por el mismo régimen jurídico y procedimiento formal general, sin tomar en consideración el tipo en que se transforma. No obstante, hemos intentado justificar en el grueso del trabajo nuestra propuesta inicial de excepcionar en este tipo específico de transformación, el destino que con carácter general prevén las leyes sobre cooperativas para los fondos irrepartibles. Sobre la base de que ambas son sociedades de economía social, participadas y controladas por los trabajadores, cuya gestión es democrática, aunque una sea de base mutualista y la otra una sociedad de capital, cuyos regímenes legales son bien distintos, pero ambas, son sociedades de trabajo asociado, con un fuerte carácter intuitu personae que les acerca a los fines sociales propuestos, independientemente de su forma jurídica.

Por lo que la transformación de una SCTA en una SL supone más una alteración en la estructura patrimonial de la sociedad que en la estructura personal, ya que la misma persona jurídica, seguramente con todos los socios o con la mayoría de ellos, continuaran el mismo proyecto empresarial, aunque bajo otra forma legal de muy parecida naturaleza jurídica.

Como hemos visto, el régimen jurídico de la transformación se articula principalmente, en torno a dos medidas de contenido económico que suponen una importante carga financiera para la sociedad resultante de la transformación y, que 
en este supuesto de hecho, al menos la segunda, puede enmendarse sin violentar en exceso la esencia del mundo cooperativo.

Si bien la primera medida económica busca garantizar que el socio disidente con el acuerdo de transformación abandone el proyecto colectivo con la menor merma económica posible, obligando a la SL a reembolsarle el valor acreditado de sus aportaciones al capital social como si de una baja justificada se tratara. La sociedad también puede atemperar este obstáculo si el capital social está constituido por aportaciones cuyo reembolso en caso de baja puede ser rehusado incondicionalmente por el Consejo Rector [art.45.1,b) LCoop]. Cuestión que no es específica del tipo de transformación que proponemos, sino que puede darse cualquiera que sea el tipo social resultante de la transformación.

La segunda medida económica que se refiere al destino que legalmente hay que dar a los fondos no repartibles entre los socios, principalmente el FRO y FEP, creemos que ha quedado justificado que no es lo más acertado en éste supuesto de transformación, tanto desde una perspectiva jurídica, como de técnica jurídica.

Por cuanto, desde una perspectiva jurídica, hay un claro paralelismo entre los fines a que debe destinarse el FEP según lo dispuesto en el artículo 56 LCoop $^{23}$ y los fines sociales que debe perseguir la SL (art. 4 LES y 18 LSLP). A lo que se une, que la carga ideológica que sustentaba la prohibición de disponer de estos fondos de forma contraria a la finalidad prevista en las leyes cooperativas, va dando paso a posturas legales más flexibles aceptándose excepciones puntuales a la hora de determinar el destino de los mismos, sobre todo, respecto al FRO. En consonancia con la progresiva aproximación entre los regímenes jurídicos de las sociedades cooperativas y las de capital, ante la necesidad de ir adaptándose al entorno competitivo y globalizado en que cualquier empresa se ve obligada a desarrollar su actividad empresarial, cualquiera que sea su forma jurídica. Superando así viejos argumentos dogmáticos que no tienen razón de ser en el actual contexto socio económico.

Las soluciones intermedias propuestas permitirán proteger de forma más racional a todos los intereses en juego. El del socio disidente, porque al ejercer su derecho de separación ha obtenido los derechos económicos que le corresponden; el resto de socios (que seguramente serán la mayoría por no decir todos), que van a continuar a través de la misma persona jurídica el mismo proyecto empresarial, aunque bajo otra forma jurídica, porque no se van a ver despojados de esos fondos que han ido generando con su esfuerzo durante la vida de la cooperativa y, por último, el movimiento cooperativo tampoco pierde, pues al ser la transformada un tipo social de la economía social esos fondos van a destinarse a la misma finalidad.

Desde una perspectiva de técnica jurídica no habría inconveniente en que los saldos del FRO se integraran en el Fondo de reserva especial que necesariamente tiene que constituir la SL (art. 14 LSLP) dado el paralelismo que ambos presentan.

23 1. El fondo de educación y promoción se destinará, en aplicación de las líneas básicas fijadas por los Estatutos o la Asamblea General, a actividades que cumplan alguna de las siguientes finalidades:

a) La formación y educación de sus socios y trabajadores en los principios y valores cooperativos, o en materias específicas de su actividad societaria o laboral y demás actividades cooperativas.

b) La difusión del cooperativismo, así como la promoción de las relaciones intercooperativas.

c) La promoción cultural, profesional y asistencial del entorno local o de la comunidad en general, así como la mejora de la calidad de vida y del desarrollo comunitario y las acciones de protección medioambiental. 
En cuanto a los saldos del FEP, es cierto que no hay un fondo específico para este menester, pero dado que las necesidades de la SL corren paralelas a las que estaba destinado este fondo en la cooperativa, nada impide que la laboral cree un fondo específico para integrar su saldo, subsistiendo la obligación de destinarlo a las mismas finalidades y quedando el buen uso de los mismos, bajo el control del Registro de sociedades laborales como una causa más de descalificación de laboral de la sociedad anónima o de responsabilidad limitada en caso contrario.

\section{Referencias bibliográficas}

Alfonso Sánchez, R. (1997) Ámbito subjetivo de la transformación en la legislación cooperativa (algunos aspectos críticos). $R d S$, $\mathrm{N}^{\circ} 8, \mathrm{pp} .178-193$.

Alfonso Sánchez, R. (2002) La transformación de la sociedad cooperativa. Madrid: Edersa. Gadea, E.; Sacristán, F. y Vargas Vasserot, C. (2009) Régimen Jurídico de la Sociedad Cooperativa del siglo XXI. Realidad actual y propuesta de reforma. Dykinson.

González-Meneses, M. y Álvarez, S. (2013) Modificaciones estructurales de las sociedades mercantiles, ( $\left.2^{\mathrm{a} e d i c i o ́ n}\right)$. Dykinson.

Lejarriaga Pérez de las Vacas, G. (1995) La sociedad cooperativa desde la perspectiva de la Alianza Cooperativa Internacional (ACI) y las sociedades laborales frente al concepto jurídico de cooperativa. Revesco. Revista de Estudios Cooperativos, No 61, pp. 89-106.

Leon Sanz, F. (2009) Capítulo VIII. Transformación, fusión y escisión de la sociedad. En Arroyo Martínez, I; Embid Irujo, J.M y Gorriz López, C. Comentarios a la Ley de Sociedades de Responsabilidad Limitada. Ley 2/1995, de 23 de marzo, de responsabilidad limitada. Tecnos, pp. 973-1065.

Llobregat Hurtado, M. L. (1991) Mutualidad y empresas cooperativas. Bosch.

Macías Ruano, A.J. (2015) El quinto principio internacional cooperativo: educación, formación e información. Proyección legislativa en España. Ciriec-España. Revista Jurídica de Economía Social y Cooperativa, № 27, pp. 243-284.

Martín López, S.; Lejarriaga Pérez de las Vacas, G. e Iturrioz del Campo, J. (2007) La naturaleza del capital social como aspecto diferenciador entre las sociedades cooperativas y las sociedades laborales. Ciriec-España. Revista de Economía Pública, Social y Cooperativa, № 58 , pp. 59-82..

Martín López, S. y Lejarriaga Pérez de las Vacas, G. (2011) Las empresas de participación de trabajo asociado ante los desafíos del futuro en un contexto de crisis económica: Propuestas de actuación. Ciriec-España. Revista de Economía Pública, Social y Cooperativa, $\mathrm{N}^{\mathrm{o}}$ 72, pp. 239-261.

Paniagua Zurera, M. y Jiménez Escobar, J. (2014) La necesidad de una legislación cooperativa adecuada: Aspectos mercantiles, tributarios y de derecho comunitario. Ciriec-España. Revista de Economía Pública, Social y Cooperativa, No 81, pp.61-94.

Paz Canalejo, N. (1994) De las cooperativas de trabajo asociado. En: Sánchez Calero, F. y Albaladejo, F. Comentarios al Código de comercio y legislación especial. Tomo XX, Vol. $3^{\circ}$.

Rodríguez Artigas, F. (2002) Transformación de sociedades cooperativas. En: Derecho de Sociedades. Libro Homenaje al profesor Sánchez Calero, Vol. IV, MacGraw-Hill Interamericana de España, pp. 4813-4851.

Rojo, A; Esteban, A. y Sánchez, J.A. (2001) La transformación de cooperativas, especial referencia al caso andaluz. Ciriec-España. Revista de Economía Pública, Social y Cooperativa, № 38 , pp.57-76. 
Rosembuj Erujimovich, T. (1995) La transformación de la cooperativa en la nueva ley de sociedades de responsabilidad limitada. La Ley. Revista jurídica española de doctrina, jurisprudencia y bibliografía, No 4, pp. 825-831.

Sacristan Bergia, F. (2010) La transformación de la sociedad cooperativa. Boletín de la Asociación Internacional de Derecho Cooperativo, No 44, pp.177-194.

Santiago Redondo, K.M. (1998) Socio de cooperativa y relación laboral. Ibidem ediciones.

Suso Vidal, J.M. (2002) El control en la transformación de las cooperativas en sociedades anónimas y limitadas. En: Derecho de Sociedades. Libro Homenaje al profesor Sánchez Calero, Vol. IV, MacGraw-Hill Interamericana de España, pp 4853-4877.

Vargas Vaserrot, C.; Gadea Soler, E. y Sacristan Bergia, F. (2017) Derecho de las sociedades cooperativas. Régimen económico, modificaciones estructurales y disolución. Wolters Kluwer.

Vargas Vaserrot, C. (2008) La solvencia y garantías de las cooperativas en el tráfico: algunas peculiaridades de su concurso, $R D C P, \mathrm{~N}^{\circ} 8$, pp. 281-294.

Ulazia Etxabe, M. (2003) Los fondos obligatorios en las sociedades cooperativas: En: Aizega Zubillaga, J. (coord.) La participación de los trabajadores en los resultados de la cooperativa. Fundación Ezai, pp.160-186. 